\title{
TU/e EnNHONEN

\section{The integration of 5G, PON and VLC technologies for ubiquitous connectivity in autonomous and cooperative systems}

\author{
Citation for published version (APA): \\ Kurbatska, I., Braunfelds, J., Bobrovs, V., Spolitis, S., Raddo, T. R., Cimoli, B., Rommel, S., \& Tafur Monroy, I. \\ (2019). The integration of $5 \mathrm{G}, \mathrm{PON}$ and $\mathrm{VLC}$ technologies for ubiquitous connectivity in autonomous and \\ cooperative systems. In IEEE 5G World Forum, 5GWF 2019 - Conference Proceedings (pp. 237-242). \\ [8911668] Institute of Electrical and Electronics Engineers. https://doi.org/10.1109/5GWF.2019.8911668
}

DOI:

10.1109/5GWF.2019.8911668

Document status and date:

Published: 01/09/2019

\section{Document Version:}

Accepted manuscript including changes made at the peer-review stage

\section{Please check the document version of this publication:}

- A submitted manuscript is the version of the article upon submission and before peer-review. There can be important differences between the submitted version and the official published version of record. People interested in the research are advised to contact the author for the final version of the publication, or visit the DOI to the publisher's website.

- The final author version and the galley proof are versions of the publication after peer review.

- The final published version features the final layout of the paper including the volume, issue and page numbers.

Link to publication

\footnotetext{
General rights

- You may freely distribute the URL identifying the publication in the public portal. follow below link for the End User Agreement:

www.tue.nl/taverne

\section{Take down policy}

If you believe that this document breaches copyright please contact us at:

openaccess@tue.nl

providing details and we will investigate your claim.
}

Copyright and moral rights for the publications made accessible in the public portal are retained by the authors and/or other copyright owners and it is a condition of accessing publications that users recognise and abide by the legal requirements associated with these rights.

- Users may download and print one copy of any publication from the public portal for the purpose of private study or research.

- You may not further distribute the material or use it for any profit-making activity or commercial gain

If the publication is distributed under the terms of Article $25 \mathrm{fa}$ of the Dutch Copyright Act, indicated by the "Taverne" license above, please 


\section{The Integration of 5G, PON and VLC Technologies for Ubiquitous Connectivity in Autonomous and Cooperative Systems}

\author{
I. Kurbatska, J. Braunfelds, V. Bobrovs, S. Spolitis \\ Institute of Telecommunications, \\ Riga Technical University, \\ LV-1048, Riga, Latvia \\ \{inna.kurbatska, janis.braunfelds, \\ vjaceslavs.bobrovs, sandis.spolitis\}@rtu.lv
}

\author{
T.R. Raddo, B. Cimoli, S. Rommel, I. Tafur Monroy \\ Institute for Photonic Integration \\ Eindhoven University of Technology \\ 5600 MB Eindhoven, The Netherlands \\ \{t.r.raddo, b.cimoli, s.rommel, \\ i.tafur.monroy\}@tue.nl
}

\begin{abstract}
The fifth-generation (5G) of mobile communications is expected to enable emerging use cases like autonomous driving vehicles, cooperative robotics, and innovative healthcare systems. These applications primarily will be available in ultra-dense urban areas, where optical fiber infrastructure is already deployed and will become part of the $5 \mathrm{G}$ ecosystem. The further integration of fiber and mobile along with optical wireless technology like visible light communications (VLC) can both enable never thought before use cases and satisfy challenging key performance indicators such as increased number of connected devices, lower energy consumption, and reduced latency. In this context, we introduce the integration of 5G, optical fiber network, and VLC technologies for creating end-to-end connectivity solutions and supporting new use cases in dense urban areas. We describe the network architecture and its functionalities upon the integrated technologies. We also describe and exploit several use cases for highly-dynamic and-densely populated urban areas that can be for the first time simplified by using the proposed integrated solution. The integration of different technologies is perceived here as a unique prospective communication platform towards ubiquitous communication with anywhere, anytime, anyhow connectivity for any use case or business case that can arise in the future.
\end{abstract}

Keywords-5G, radio-over-fiber, mm-Wave, Li-Fi, VLC, C-RAN, PON, autonomous driving vehicles

\section{INTRODUCTION}

The fifth-generation (5G) mobile communications will have a great impact in different use cases such as stadiums, hospitals, railway stations, and homes as well as businesses using conventional wireless access technology [1]-[3]. 5G will feature data transmissions up to tens of gigabits, ultralow latency, and high-reliability communication. On one hand, this will change and significantly improve several different applications like Internet of Things, augmented and virtual reality, and super high-resolution video streaming [1][3]. On the other hand, 5G technology still needs to satisfy stringent key performance indicators (KPIs) such as higher bandwidth and data-rate per user, increased number of connected devices, lower energy consumption, and reduced end-to-end latency [3]. Unlicensed or slightly licensed millimeter-wave (mm-Wave) frequency bands, including the $\mathrm{K} / \mathrm{Ka}$-band $(24.25$ - $27.50 \mathrm{GHz})$ - the $5 \mathrm{G}$ NR n258, V-band region $(\sim 60 \mathrm{GHz})$, the $\mathrm{W}$-band $(75-110 \mathrm{GHz})$, for radioover-fiber (RoF) link deployment are key candidates for $5 \mathrm{G}$ fronthaul networking as well as part of the solution to satisfying these KPIs [4], [5].

Considering the required capabilities of $5 \mathrm{G}$ networks and their techniques, optical fiber becomes the primary complement for $5 \mathrm{G}$ fronthaul and backhaul networking [6],
[7]. While the passive optical network (PON) is a costefficient, mature, and the most widespread access architecture being deployed worldwide with even more recent massive deep fiber installations near end-user premises [8]-[10], 5G systems roll-out are still under development. Although one of the most accepted data rates used in PON is $2.5 \mathrm{~Gb} / \mathrm{s}$, the revenue on the $10 \mathrm{~Gb} / \mathrm{s}$ equipment is increasing (please see Fig. 4). Moreover, standardizations bodies are working on PON solutions at line bit rates higher than $10 \mathrm{~Gb} / \mathrm{s}(100 \mathrm{~Gb} / \mathrm{s}$ and higher) [11], while according to [7], [12] the target bit rates for $5 \mathrm{G}$ are up to $25 \mathrm{~Gb} / \mathrm{s}$. Consequently, PON has become a crucial complementary candidate for successful $5 \mathrm{G}$ fronthaul deployment also for meeting the required 5G KPIs.

The Electronic Communications Committee of the European Conference of Postal and Telecommunications Administrations (CEPT) has recently harmonized the first bands for $5 \mathrm{G}$ applications [13]. These bands are $3.4-3.8 \mathrm{GHz}$ (3.6 GHz central carrier) and $24.25-27.5 \mathrm{GHz}(26 \mathrm{GHz}$ central carrier). Furthermore, the CEPT has identified the 26 $\mathrm{GHz}$ band for early European harmonization as it provides over $3 \mathrm{GHz}$ of contiguous spectrum and more favorable propagation than the higher frequency bands also under consideration. In addition to the $26 \mathrm{GHz}$ band, the $28 \mathrm{GHz}$ band has emerged as the second most important band for $5 \mathrm{G}$ networks. However, the latter is mainly considered in the United States (27.5 - 28.35 GHz), Japan (27.5 - 29.5 GHz), and South Korea (26.5 - $29.5 \mathrm{GHz})$ [2], [14]. Noteworthy, considerable attention has been drawn to $60 \mathrm{GHz}$ band when $5 \mathrm{G}$ indoor applications are targeted like, for example, remote robot control, cooperative robotics, and intra vehicular communication. These applications do handle very large volumes of traffic data in a reliable and ultra-low latency way [15].

In the meanwhile, visible light communication (VLC) technology, including light-fidelity (Li-Fi), has recently received considerable attention as an alternative solution for $5 \mathrm{G} \mathrm{mm}$-Wave [16]-[18] or as a complimentary technology to be merged with $5 \mathrm{G}$ instead of replacing it. This is because VLC/Li-Fi has several interesting benefits such as no frequency license required, free electromagnetic interference, and ease as well as fast deployment. In addition, the use of VLC grants greater bandwidth allowance in comparison with radio frequency (RF) systems (380 - $780 \mathrm{~nm})$, and can support high data rates (tens of gigabits or even higher), as a result, compatible with $5 \mathrm{G} \mathrm{KPIs} \mathrm{providing} \mathrm{low} \mathrm{latency} \mathrm{and}$ long service life. Finally, it is still worth mentioning that unlike other wireless technologies, VLC/Li-Fi is considered safe for human health and does not affect the functionality of highly sensitive electronic systems and consequently can be used in RF restricted places [16], [17]. 
Several different applications have been tackled with Li-Fi technology, especially those requiring high data rate indoor links for fast Internet connections. Moreover, Li-Fi is currently receiving special attention within intelligent transport systems and smart mobility such as autonomous driving vehicles that use communication and analysis the traffic data to improve the efficiency of the transportation system and therefore, to reduce $\mathrm{CO}_{2}$ emissions [16], [17]. Indeed, Li-Fi systems can be deployed for fast data broadcast and communication between vehicles and/or between traffic infrastructures and vehicles, the so-called vehicle-to-vehicle $(\mathrm{V} 2 \mathrm{~V})$ and vehicle-to-infrastructure (V2I) communication systems [16]. Furthermore, the significant advantage of VLC enabled by light emitting diodes (LEDs) enables the use of already existing lighting infrastructure in smart factories with cooperative robotics and Industry 4.0. In this fashion, VLC networks can be considered energy efficient, as they do not use extra energy for data transmission, except the energy already used for the lighting. Note that LEDs are already widely used in vehicle lighting systems and traffic lights [16], [17]. Finally, VLC technology is compatible with traditional radio frequency systems in the way that they can complement each other for creating heterogeneous networks [16].

Within this context, in this paper, we propose the integration of different technologies to provide ubiquitous end-to-end connectivity in any sort of use case scenario with focus on densely populated urban areas. We propose an innovative optical network end-unit, ONt-X Box, which is multifunctional and software-defined networking (SDN)controlled capable of supporting both traditional technologies like $\mathrm{WiFi}$ and Ethernet as well as new VLC/Li-Fi and $5 \mathrm{G}$ systems. Accordingly, we introduce the integration of $5 \mathrm{G}$, $\mathrm{PON}$, and $\mathrm{VLC} / \mathrm{Li}-\mathrm{Fi}$ technologies as part of a unique network architecture design to support current and emerging use cases. We describe the new network architecture considering the integrated technologies and explain its features. These features include radio-over-fiber (RoF), wavelength division multiplexing, space division multiplexing (SDM) based on ribbon and multicore fibers (MCF), mm-Wave fronthaul, and time-division multiplexing. We further describe several use cases such as autonomous driving vehicles and cooperative robotics that can be enabled by the proposed integrated solution. The proposed solution enables, for the first time, ubiquitous communication with anywhere, anytime, anyhow connectivity for current and unforeseen future use cases.

\section{TECHNOLOGIES ENABLING AUTONOMOUS DRIVING AND COOPERATIVE ROBOTICS SOLUTIONS}

This section addresses the integration of different technologies (5G, PON, and VLC) as an elegant alternative network solution to enable autonomous driving solutions, cooperative robotics in smart factories, and open-sky environments with multiple robots/drones interconnected in a centrally controlled network to share common resources and tasks. For example, the proposed integrated network can be useful for addressing cooperative autonomous robots/drones, where ultra-low latency and super-high throughput capabilities must be ensured in a centralized (cloud controlled) manner for highly dynamic and dense environments [18].

\section{A. Visible Light Communication Technology}

The VLC technology employs visible light as a carrier for the data and is considered a promising alternative to the existing RF-based wireless systems. The general structure of a VLC network is shown in Fig. 1 [19]. A LED that is used for lighting purposes can be transformed into a VLC transmitter by adding an encoder (in the simplest case microcontroller) and a digital power switch [16]. The encoded data signal is used to drive an LED. As a result, the electrical data signal is converted into an intensity modulated optical signal [19]. In the simplest approach, on-off keying (OOK) modulation is employed as it is considered simple to implement, but advanced modulation formats can also be considered [16]. The obtained modulated optical signal is transmitted through the VLC channel with line-of-sight (LoS). At the receiver side, the optical signal is filtered by optical filter (OF) to remove the unwanted spectrum components (e.g. infrared) and then by using lens is focused on a photodetector (PD) obtaining the electrical data signal, that further is demodulated and decoded by the decoder (in simplest case - microcontroller) [17], [19]. VLC systems are regarded as a promising candidate for V2V and V2I communications in autonomous vehicles networks [18].

\section{B. 5G Cloud RAN Architecture}

In order to address the challenges, mobile network operators, as well as equipment vendors, have given significant attention to small-cell schemes based on centralized/cloud radio access network (C-RAN), where traditional base station (BS) function is split into two parts: centralized baseband unit (BBU) and remote radio unit (RRU) as illustrated in Fig. 2 [6], [12], [20], [21]. In general, a C-RAN fronthaul architecture regards the relocation of BBUs from the RRH premises to the central office (CO) site creating a centralization of BBUs. Such a paradigm can grant the network several advantages like higher flexibility and manageability, space released in the RRH and power consumption reduction. The (remote) radio units or radio heads (RHs) are connected to BBUs using analog or digital radio-over-fiber (A-RoF or D-RoF) techniques and protocols [22]. Moreover, 5G new radio (NR) transport architecture assumes the share of BBU functions between the central unit (CU) and distributed unit (DU), and also remote radio unit (RRU). Specific functions residing in CU and DU, see inset in Fig. 2, are deployment dependent and still under discussions [21]. Early investigations of RoF technologies were mainly focused on providing wireless backhaul solutions using fiber feeder networks, while with the development of $5 \mathrm{G}$ mobile communications the demand on

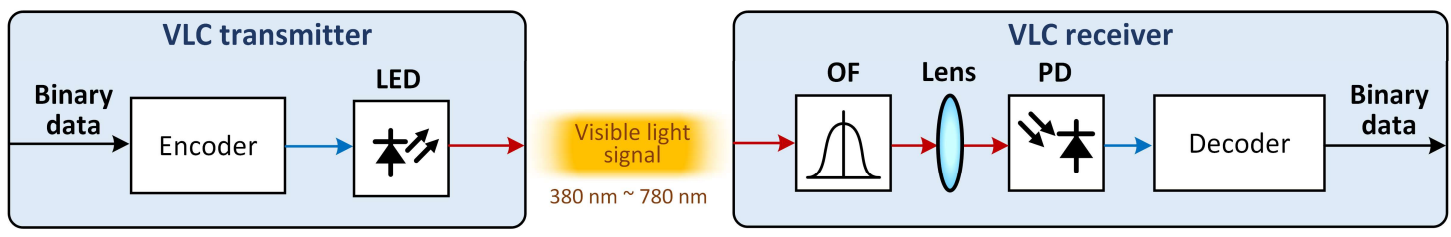

Fig 1. General structure of visible light communication systems. 


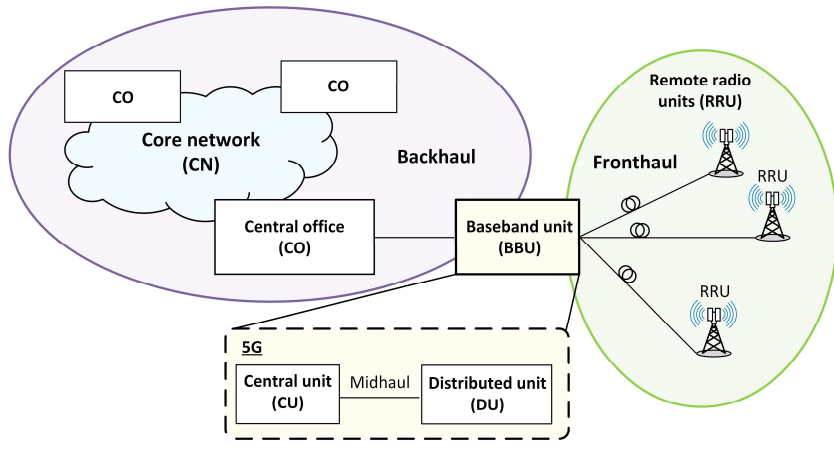

Fig. 2. General overview of $5 \mathrm{G}$ mobile system architecture.

the capacity of fronthaul links has increased significantly [20]. The network between RRU and DU is considered a fronthaul, while the midhaul connects DU with CU, but backhaul - CU with 5G CN (Core Network) or CUs between themselves, as shown in Fig. 2 [21].

According to [12], backhaul and midhaul transport requirements are similar, while fronthaul requirements should be considered separately. The target capacities for midhaul and backhaul are up to $5.7 \mathrm{~Gb} / \mathrm{s}$ for a single radio unit (considering transport overhead). While for the fronthaul the capacity of $25 \mathrm{~Gb} / \mathrm{s}$ has to be ensured. Respectively, user data rates should reach $1 \mathrm{~Gb} / \mathrm{s}$ for a few devices and $25 \mathrm{Mb} / \mathrm{s}$ for up to 30.000 users, highly concentrated in hot-spot areas like for example football stadiums [4]. Moreover, fronthaul requires very low latency [12]. These KPIs (data rates and latency) are key enablers for applications such as autonomous driving and cooperative robotics [23].

\section{Technologies Integration}

5G systems based on C-RAN architecture and their small cells densification push the demand on the transport architecture that is more efficient than previously used pointto-point fiber. Therefore, PON providing optical fiber connectivity near or very close to the antenna premises such as fiber-to-the-antenna (FTTA), becomes the preferable, cost-effective solution for the $5 \mathrm{G}$ transport [6], [12]. Moreover, PON is considered to be a feasible solution for the cost-effective integration of C-RAN into the already deployed deep fiber infrastructure. Respectively, both scenarios - dedicated optical-distribution network (ODN) and $5 \mathrm{G}$-overlaid PON in the existing ODN using a wavelength coexistence element are completely possible [6], [12]. In the case of shared ODN, it is possible to support one or at most a few cells per ODN, while in the case of dedicated ODN, at least 8 cells need to be aggregated [12]. In the terms of the

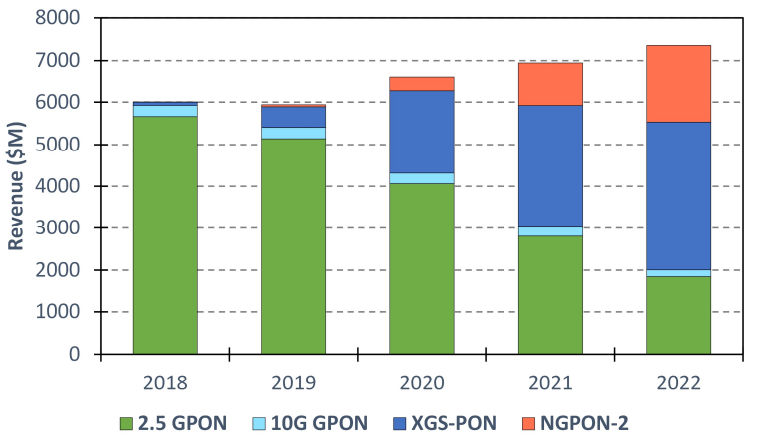

Fig. 4. Revenue forecast of GPON, 10G GPON, XGS-PON and NGPON-2 optical access network technologies [8].

access network, mobile fronthaul are based on FTTA links with optical fibers are deployed very close to the antenna premises connecting fibers from the $\mathrm{BBU}$ (located in $\mathrm{CO}$ ) to antennas in the RRH.

According to [6], both types of PON - time-division multiplexed PON (TDM-PON) and wavelength-division multiplexed PON (WDM-PON) are feasible for mobile fronthaul [6]. Figure 3 shows both network schemes. The TDM-PON is a lower cost solution for bit rates of up to 10 $\mathrm{Gb} / \mathrm{s}$ for small cell clusters. However, it is not cost-effective for the sparsely deployed small-cell network. In contrast, the advantages of WDM-PON include high flexibility in terms of protocol and transmission data rate, high capacity, improved security, and low latency link. Therefore, WDM-PON stands out as a preferable solution for the next-generation mobile fronthaul network requiring high capacity and low latency. Noteworthy, the overlay of combined time and wavelength division multiplexed PON (TWDM-PON) and dense DWDM-PON sharing the same ODN simultaneously is also possible [6].

Moreover, the PON based on TDM (especially, GPON) is widely deployed and hence produces the largest share of the revenue for telecom operators so far, as can be noticed in Fig. 4. However, the demand for next-generation NG-PON2 standard based on WDM technique will certainly increase, as the latter is capable to support higher reliability, scalability, flexibility as well as bandwidth and power efficiency [8].

Besides the TDM and WDM the utilization of the advanced technologies such as optical code-division multiple-access (OCDMA) in PON are considered to be an efficient solution for the access networks there lowbandwidth services are expected to coexist with the broadband networking applications [9], [10], [26].

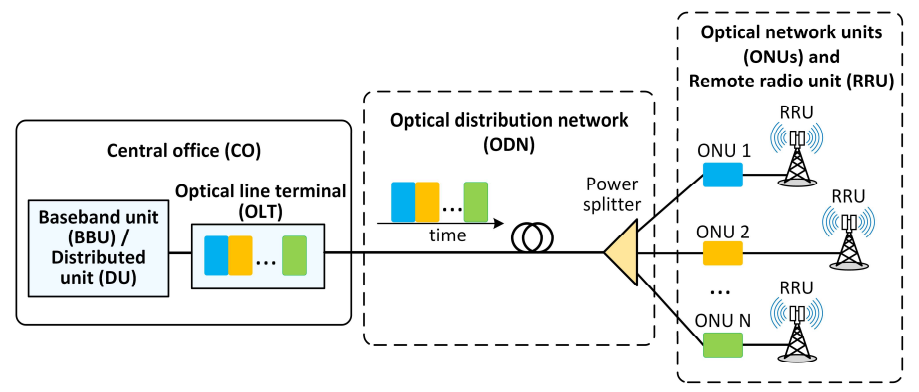

(a) Mobile fronthaul over TDM-PON network

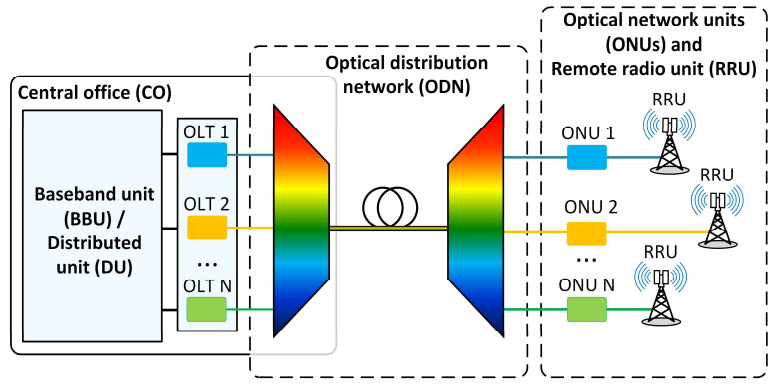

(b) Mobile fronthaul over WDM-PON network

Fig. 3. Comparison of (a) mobile fronthaul over time-division multiplexing PON and (b) mobile fronthaul over wavelength-division multiplexing PON. 
Consequently, the utilization of OCDMA in PON for 5G applications can be considered as a possible direction for future research.

Regardless of the PON technique, the implementation of PON architecture requires careful design to prevent additional latency and radius power loss that can limit the cell size. These impairments are mainly due to the optical power splitters being employed to separate and collect optical signals in the PON systems [6]. In addition to an intermediate frequency (IF)-over-fiber transmission scheme, there are also in the literature reports on RF-over fiber fronthaul links targeting mm-Wave wireless signal transmission for $5 \mathrm{G}$ applications [20]. 5G integrated with PON systems have been demonstrated in [24] and [25]. The realized system employs GPON signals at $2.5 \mathrm{~Gb} / \mathrm{s}$ and a RoF signal of up to $10 \mathrm{~Gb} / \mathrm{s}$ demonstrating their huge potential for $5 \mathrm{G}$ applications. In these networks, the $5 \mathrm{G}$ data signal is modulated by using quadrature M-QAM modulation formats [24], [25]. In the CO part, both GPON and 5G signals are coupled with wavelength coexistence element [24]. The RF antenna radiates RoF signals afterward to the end-user devices [24]. Nonetheless, these networks [24] and [25] have highfrequency radio oscillators, located in end-user premises, therefore making the receiver structure more complicated and decentralized.

\section{5G Fronthaul Main Technologies}

The following technologies are considered to be deployed as part of the new 5G C-RAN network concept: WDM, SDM, MCFs, SDN, VLC, multiple-input-multiple-output signaling (MIMO), and adaptive beamforming technology [23]. The 5G C-RAN infrastructure can support larger network capacity over smaller cells such as densely deployed short-range base stations using mm-Wave frequencies. For example, a large number of RRH antennas can be deployed surrounding stadium premises or shopping malls so that the whole area can be covered with the help of mm-Wave technology [22].

Normally, a RoF network based on mm-Wave transmits a digital baseband signal through a fiber link, undergoes optical to electrical conversion $(\mathrm{O} / \mathrm{E})$, digital to analog conversion and upconversion to the radio frequency, and then is radiated and detected. Thereby, the $\mathrm{O} / \mathrm{E}$ conversion represents the transition from the fiber link to a radio frequency signal at mmWave frequencies, which denotes the main step in bringing advantages to RoF-based networks. The 5G C-RAN fronthaul can operate in the mm-Wave range with multiple bands within the frequency range of 20 to $300 \mathrm{GHz}$ [22]. The approximate coverage areas are up to a few kilometers within $\mathrm{K} /$ Ka-band, i.e., the $5 \mathrm{G} \mathrm{NR} \mathrm{n} 258$ band and up to a few hundreds of meters within the V-band region [23].

\section{INTEGRATED SOLUTION AND NETWORK ARCHITECTURE FOR AUTONOMOUS AND COOPERATIVE SYSTEMS}

In this section, we introduce and explore the proposed network architecture that ensures integration of $5 \mathrm{G}$ and $\mathrm{VLC} / \mathrm{Li}-\mathrm{Fi}$ systems over PON infrastructure. Figure 5 illustrates the new solution based on an ONU element called here by optical network to-the-X (ONt-X) Box. The ONt-X is a multifunctional, centrally SDN-controlled communication unit, capable of providing well-known services such as $\mathrm{Wi}-\mathrm{Fi}$, Ethernet (depicted in Fig. 5 as baseband) and new services like $\mathrm{VLC} / \mathrm{Li}-\mathrm{Fi}$ and $5 \mathrm{G}$ in sub-6 GHz, K/Ka, and V-bands.

This unique communication box, composed of complex photonic integrated circuits, is capable of achieving peak bitrates up to $100 \mathrm{~Gb} / \mathrm{s}$, can operate in most mm-Wave bands, has MIMO and beamforming functionalities, satisfy several different network topologies, and can be fully operated remotely via its SDN capabilities. This elegant integrated solution aims to innovate optical wireless systems development for future use cases and $5 \mathrm{G}$ and beyond applications, compatible with legacy systems, and being suitable for densely-built urban areas, hot spots, and unforeseen scenarios.

The integrated technology box paves the way towards a truly efficient fronthaul infrastructure for next generation mobile optical wireless systems. Furthermore, the combination of different technologies grants extra benefits to a network. For example, the Li-Fi functionality of the ONt-X Box provides bidirectional and secure transmissions, and have ease deployment since data communication can be achieved via conventional LEDs used initially for illumination purposes. The visible light technology defined by the IEEE 802.15.7 standard, has almost unlimited bandwidth capacity and low power consumption compared to traditional $\mathrm{Wi}-\mathrm{Fi}$ systems, and is considered cost-efficient since it takes advantage of already deployed LEDs. A complex range of use cases that can be enabled by the integrated technology box is illustrated in Fig. 6.

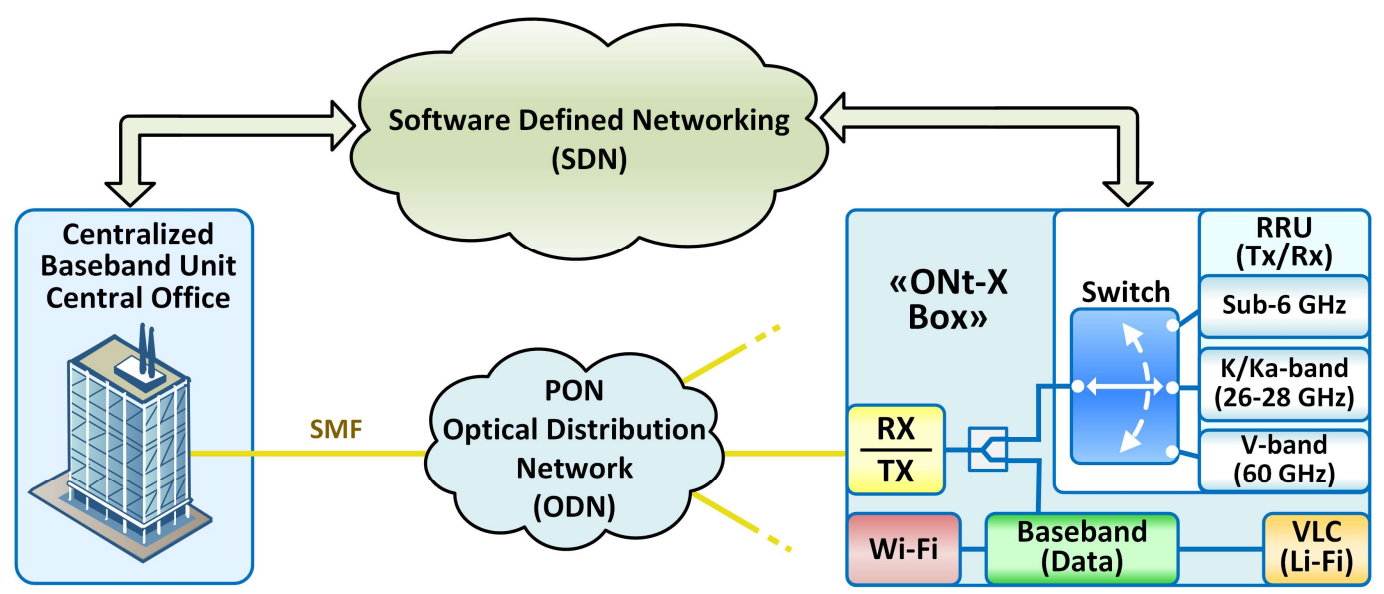

Fig. 5. C-RAN architecture over legacy PON infrastructure and end-user equipment (ONt-X box) capable to simultaneously provide multiple enduser solutions like Wi-Fi, VLC/Li-Fi, traditional data (baseband) and wireless sub-6 GHz and mm-Wave communication. 


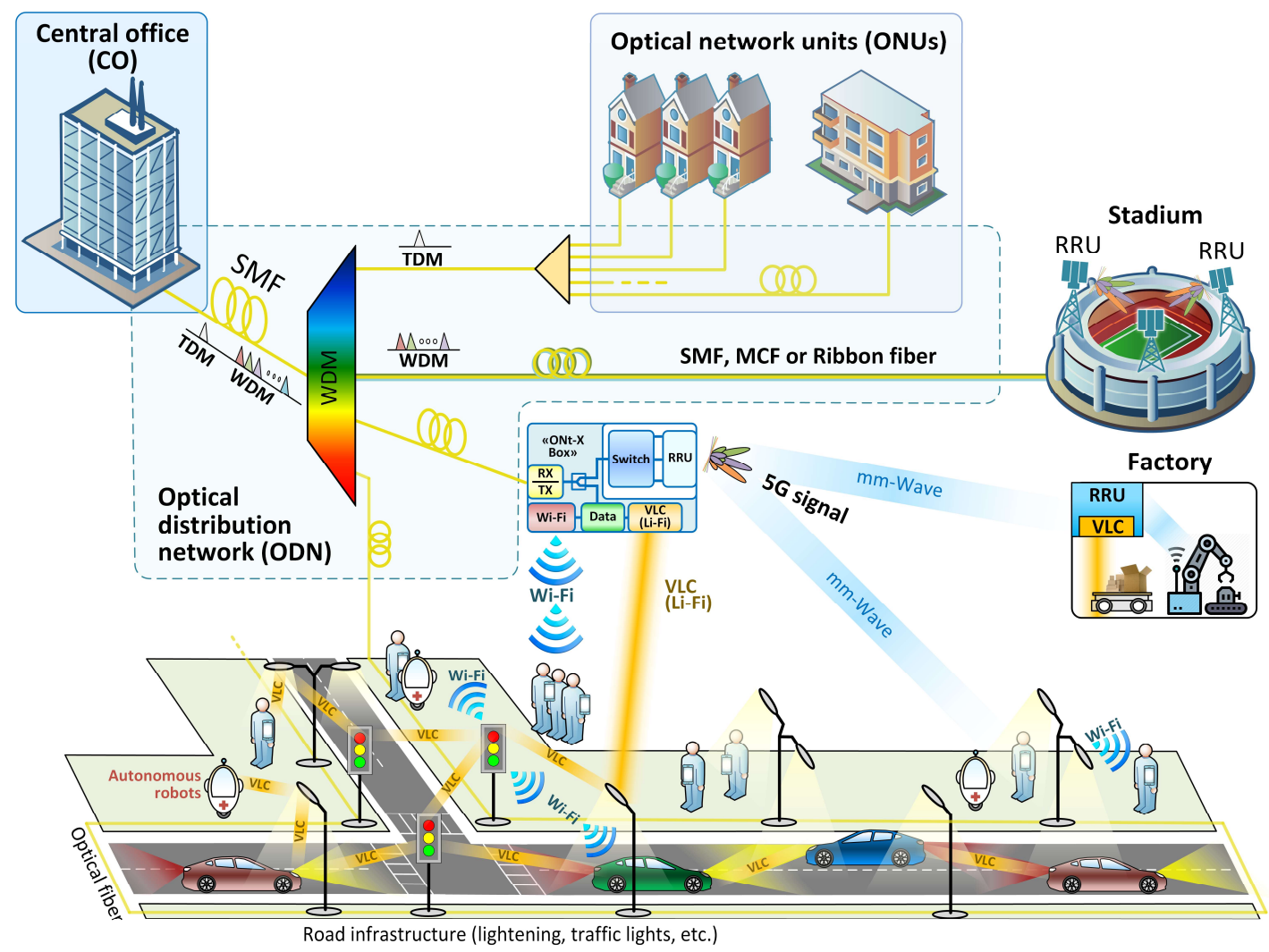

Fig. 6. Use case scenarios using the integrated technology solution based on 5G, VLC, and PON for autonomous driving vehicles and cooperative robotics.

The ONt-X Box supports a new network architecture that by its turn accommodates different use cases as a result of the coexistence of different communication technologies. Moreover, the use of the integrated Li-Fi/VLC system as shown in Fig. 6 can be useful to further address the lack of RF spectrum resources faced nowadays with the advent of new applications and unforeseen number of simultaneous connections that will result in a spectrum crunch. Accordingly, the visible spectrum is immensely larger than RF spectrum and can accommodate the huge data traffic volume generated by emerging use cases based on autonomous driving vehicles for example.

It is expected that vehicles will soon generate an amount of data traffic in the order of petabytes and only an integrated solution scheme will be able to handle such a large data volume. Note that $\mathrm{Li}-\mathrm{Fi}$ is considered a complimentary technology to operate in combination with $5 \mathrm{G}$ systems, as part of a heterogeneous network for supporting ubiquitous connectivity. Finally, Li-Fi/VLC technology can be not only suitable for intra vehicle connectivity, but also for vehicle-tovehicle, and vehicle-to-infrastructure communication such as the connectivity among vehicles and intelligent traffic lights depicted in Fig. 6. Li-Fi is further exploited here to provide connectivity for autonomous robots and automated smart factory also known as Industry 4.0 with robots communicating among one another via visible light. Regardless of the use case, the data from the BBU in the 5G C-RAN networks is sent via ODN of the PON network as an optical channel. In PON networks the transmission medium can be standard single mode optical fiber (e.g. ITU-T G.652, G.655, G657 fibers, already widely deployed in legacy PON) and ribbon fiber or multicore optical fibers to provide an extra dimension of data multiplexing via SDM functionalities.
Conventional D-RoF cellular systems, where common public radio interface (CPRI) processing at the RU imposes a bottleneck in network performance, will be replaced by ARoF solutions to eliminate the digital processing at the RU [23]. In addition, the adoption of A-RoF avoids the need for high-speed analog to digital conversion and additional modulation/demodulation stages at the remote site, which is highly demanding in terms of energy consumption [19]. According to [4], A-RoF provides a much more beneficial functional split, larger bandwidth and significant cost savings thus becoming a natural candidate for the generation of mmWave signals [3], [4].

To ensure the maximal possible centralization and to simplify the ONt-X Box ensuring its cost-efficiency, we base our architecture on the generation of mm-Waves in the transmitter located in CO utilizing the baseband data. Several distinct methods of mm-Wave signal generation in A-RoF systems can be used as proposed in [4]. It allows transporting an intermediate frequency signal over the fiber, rather than the target RF frequency. By utilizing the mentioned approach, the optical A-RoF signal is sent through the ODN of the PON and at the optical receiver (with square law detection), the electrical signal at desired $\mathrm{mm}$-Wave frequencies as well as at baseband is obtained. The optical receiver contains a photodiode, where the heterodyne photonic up-conversion is realized and the RF signal is generated directly in the receiver.

In the ONt-X Box, we separate baseband, sub-6 GHz and $\mathrm{mm}-$ Wave signals by using appropriate electrical filters. Thus, baseband signal can be sent via Wi-Fi or VLC, while the sub$6 \mathrm{GHz}$ signal and mm-Wave signal via RRU. The frequency band of the transmitted RF signal, whether it is sub 6-GHz, Kband or V-band mm-Wave signal can be defined by SDN, simultaneously setting an appropriate frequency of the tunable 
local oscillator in the transmitter and switching to an appropriate antenna at RRU in "ONt-X Box".

In the heterogeneous network scenario shown in Fig. 6, the proposed ONt-X Box is placed into the converged PON as one wavelength channel. Through this channel, the ONt-X Box receives optical data signal at one frequency and tunable LO signal at another frequency, where the frequency spacing between these two signals is equal to the desired mm-Wave frequency. In this coexistence scenario existing PON technologies like 2.5G GPON, 10G GPON, XGS-PON (socalled legacy PON channels) can be provided in the same ODN together with the RoF signals deployed on their own channels by using WDM [27].

In this scenario, instead of using the several SMF fibers for each channel divided by a demultiplexer, we use SDM (using ribbon or MCF fibers) to transmit several RoF signals to the hot-spot areas like stadium premises, smart factories, busy streets, and dense urban areas. Fig. 6 addresses the possible applications and use cases enabled by the ONt-X Box in $\mathrm{mm}$-Wave communications and coexistence networking for factories with cooperative robots, V2V and V2I communication as well medical assistant robots for humans, which can be interconnected in a centralized manner through VLC, Wi-Fi or $5 \mathrm{G}$ (sub-6 GHz or mm-Wave) technologies.

\section{CONCLUSIONS}

In this paper, we proposed and introduced a new solution for technology integration of $5 \mathrm{G}$ mobile systems, PON, and VLC systems. The new network architecture design, use case scenarios, and integrated solution box were addressed. Moreover, the main features of 5G C-RAN fronthaul networking were also addressed. We further introduced the architecture of next generation optical network end-unit, the so-called ONt-X Box, which is multifunctional and SDNcontrolled capable of handling both traditional technologies like $\mathrm{Wi}-\mathrm{Fi}$ as well as Ethernet, and VLC/Li-Fi and $5 \mathrm{G}$ systems including sub- $6 \mathrm{GHz}, \mathrm{K} / \mathrm{Ka}$, and $\mathrm{V}$ bands. This integrated solution paves the way towards ubiquitous communication with anywhere-anytime-anyhow connectivity not only for autonomous driving vehicles and cooperative robotics, but for any unforeseen use/business case that may arise in the future.

\section{ACKNOWLEDGMENT}

This work was partially funded by the European Regional Development Fund within the Activity 1.1.1.2 "Post-doctoral Research Aid" of the Specific Aid Objective 1.1.1 "To increase the research and innovative capacity of scientific institutions of Latvia and the ability to attract external financing, investing in human resources and infrastructure' of the Programme "Growth and Employment" (No. 1.1.1.2/VIAA/1/16/044). Also partially funded by the blueSPACE and 5G-PHOS 5G PPP projects under grant agreements number 762055 and 761989.

\section{REFERENCES}

[1] J. S. Wey and J. Zhang, "Passive optical networks for 5G transport: technology and standards," in Journal of Lightwave Technology, vol. 37, no. 12, pp. 2830-2837, June, 2019.

[2] GSM association (GSMA), "Study on socio-economic benefits of 5G services provided in mmWave bands," research report, available online, pp. 1-64, December, 2018

[3] N. Argyris et al., "A 5G mmWave fiber-wireless IFoF analog mobile fronthaul link with up to $24 \mathrm{~Gb} / \mathrm{s}$ multi-band wireless capacity," Journal of Light. Technology, vol. 37, no. 12, pp. 2883-2891, 2019.
[4] S. Rommel, T. R. Raddo and I. T. Monroy, "The fronthaul infrastructure of 5G mobile networks," in Proc. CAMAD, Spain, 2018.

[5] I. F. da Costa et al., "Photonics-assisted wireless link based on mmwave reconfigurable antennas," in IET Microwaves, Antennas \& Propagation, vol. 11, no. 14, pp. 2071-2076, 2017.

[6] I. A. Alimi, A. L. Teixeira and P. P. Monteiro, "Toward an efficient CRAN optical fronthaul for the future networks: a tutorial on technologies, requirements, challenges, and solutions," Communications Surveys \& Tutorials, vol. 20, no. 1, 2018.

[7] P. Chanclou, L. Anet Neto, K. Grzybowski, Z. Tayq, F. Saliou, and N. Genay, "Mobile fronthaul architecture and technologies: A RAN equipment assessment," J. Opt. Commun. Netw., vol. 10, no. 1, 2018.

[8] A. Weissberger, IEEE Communications Society, Technology Blog, May 28, 2017. Online - http://techblog.comsoc.org/2017/05/

[9] A. Jurado-Navas, T. R. Raddo, J. M. Garrido-Balsells, B.-H. V. Borges, J. J. Vegas Olmos, and I. Tafur Monroy, "Hybrid optical CDMA/FSO communications network under spatially correlated gamma-gamma scintillation", Optics Express, vol. 24, no. 15, pp. 16799-16814, 2016.

[10] L. Galdino et al., "Performance comparison of hybrid 1-D WDM/OCDMA and 2-D OCDMA towards future access network migration scenario," in Proc. ICTON, Coventry, England, 2012.

[11] S. Barthomeuf, F. Saliou, L. A. Neto, G. Simon, F. Bourgart, P. Chanclou, and D. Erasme, "Equalization and interoperability challenges in next generation passive optical networks," in Optical Fiber Communication Conference, paper W4J.4, 2019.

[12] E. Harstead, D. van Veen, V. Houtsma and P. Dom, "Technology roadmap for time-division multiplexed passive optical networks (TDM PONs)," in Journal Lightwave Tech., vol. 37, no. 2, pp. 657-664, 2019.

[13] The Electronic Communications Committee (ECC) of the European Conference of Postal and Telecommunications Administrations (CEPT), "Spectrum for wireless broadband - 5G", March 2019.

[14] P. Marsch, O. Bulakci, O. Queseth, and M. Boldi, "5G system design architectural and functional considerations and long term research," Wiley, 2018.

[15] X. Wu et al., "60-GHz millimeter-wave channel measurements and modeling for indoor office environments," in IEEE Transactions on Antennas and Propagation, vol. 65, no. 4, pp. 1912-1924, April 2017.

[16] A. Cailean and M. Dimian, "Current challenges for visible light communications usage in vehicle applications: a survey," in IEEE Commun. Surveys Tuts., vol. 19, no. 4, pp. 2681-2703, 2017.

[17] N. Wang, Y. Qiao, W. Wang, S. Tang and J. Shen, "Visible light communication based intelligent traffic light system: designing and implementation," in Proc. ACP, Hangzhou, 2018.

[18] I. T. Monroy et al., "Testing facilities for end-to-end test of vertical applications enabled by 5G networks: Eindhoven 5G Brainport testbed," in Proc. ICTON, Bucharest, Romania, 2018.

[19] X. Li, R. Zhang and L. Hanzo, "Optimization of visible-light optical wireless systems: network-centric versus user-centric designs," in Communications Surveys \& Tutorials, vol. 20, no. 3, 2018.

[20] C. Lim, Y. Tian, C. Ranaweera, T. A. Nirmalathas, E. Wong and K. Lee, "Evolution of radio-over-fiber technology," in Journal of Lightwave Technology, vol. 37, no. 6, pp. 1647-1656, March, 2019.

[21] ITU-T, "Transport network support of IMT-2020/5G," Int. Telecommun. Union, Switzerland, Tech. Rep. GSTR-TN5G, 2018.

[22] A. Morales, D. Konstantinou, S. Rommel, T. R. Raddo, U. Johannsen, C. Okonkwo and I. Tafur Monroy, "Bidirectional K-band photonic/wireless link for 5G communications," in Proc. IRMMWTHz, Paris, France, 2019.

[23] T. R. Raddo, S. Rommel, C. Vagionas, G. Kalfas, N. Pleros, and I. T. Monroy, "Analog radio-over-fiber 5G fronthaul systems: blueSPACE and 5G-PHOS projects convergence", in Proc. EUCNC, 2019.

[24] R. N. Da Silva, M. S. B. Cunha, I. F. da Costa and S. A. Cerqueira, "GPON-based front-end architecture for 5G networks," in IMOC 2017.

[25] R. M. Borges et al., "Integration of a GFDM-based 5G transceiver in a GPON using radio over fiber technology," in Journal of Lightwave Technology, vol. 36, no. 19, pp. 4468-4477, Oct., 2018.

[26] T. R. Raddo, A. L. Sanches, I. T. Monroy, and B.-H. V. Borges, "Throughput performance evaluation of multiservice, multirate OCDMA in flexible networks," Photonics Journal, vol. 8, no. 1, pp. 115, February 2016.

[27] S. Spolitis and G. Ivanovs, "Extending the reach of DWDM-PON access network using chromatic dispersion compensation," in Proc. Swedish Communication Technologies Workshop, Stockholm, 2011. 